\title{
An instability mechanism for drumlin formation
}

\author{
A. C. Fowler \\ University of Oxford, Mathematical Institute, \\ 24-29 St. Giles', Oxford OX1 3LB, England
}

April 25, 2000

EMAIL: fowler@maths.ox.ac.uk

TEXT LENGTH: 23 PAgES DOUBle SPACED

RUNNING HEAD: Drumlin formation

\begin{abstract}
Drumlins are subglacial bedforms which are formed by the interaction of ice flow with an erodible basal topography. The mechanism of their formation bears resemblance to similar processes which cause the formation of dunes and anti-dunes in rivers, and sand dunes in deserts. Recently Hindmarsh (1998a) showed that the interaction of a shearing ice flow with a deformable basal till layer could cause an instability which promotes the growth of basal topography, though he was unable to give analytic criteria for the instability. Here we analyse Hindmarsh's model, and by using certain approximations, we are able to give concise analytic parametric criteria for this instability. The resultant instability occurs if the basal shear stress is larger than a critical value which increases with increasing basal effective pressure, and which also depends on the basal till thickness. It is hypothesised that this instability is the basic mechanism involved in the formation of Rogen moraine and drumlins.
\end{abstract}

Theories for the origin of drumlins (figure 1) have been debated in the geological literature for over a hundred years. Early authors (Russell 1895, Millis 1911, Tarr 1894, Upham 1892) associated their formation with erosion or deposition of basal till. A summary of the early work is given by Gravenor (1953), together with an assessment of the relative merits of the erosional and depositional theories. An extensive survey of the literature is that of Everett (1987). The books by Sugden and John (1976) and Embleton and King (1975) give useful discussions, both of the physical nature 
of drumlins, and of the various theories concerning their formation. As Sugden and John point out, the dynamical theories are conspicuously unsatisfactory.

More recently, the erosion/deposition type theories have been fused by Boulton (1987), who suggests that the mechanism of drumlin formation is associated with the deformational behaviour of subglacial tills, an idea previously advanced by Smalley and Unwin (1968) and Menzies (1979), and evidentially supported by Boyce and Eyles (1991).

A radical alternative is the phenomenological flood theory of Shaw and co-workers (Shaw 1983, 1994; Shaw and Kvill 1984, Shaw et al. 1989), who suggest, on the basis of a perceived similarity with fluvially eroded bed forms, that drumlins are formed similarly, in massive subglacial floods. This idea has been supported by Sharpe (1987), for example. The plausibility of this theory relies primarily on the existence and nature of such large floods; and while it is undeniable that floods, such as jökulhlaups, do occur, their erosive effects remain hypothetical.

The present paper offers an orthogonal approach to the dynamics of drumlin formation. Although the opposing till deformation or flood-derived theories are closer to a quantitative theory than earlier more discursive ideas, they are still a long way short of a genuine dynamical description. Such a description was initiated by Hindmarsh (1996, 1998b); in particular, the latter paper offers an extended effort to bridge the conceptual gap between the geomorphologist and the applied mathematician. While such bridge-building is essential, we do not seek to embroider the present content in this way. In the custom of the dynamicist, we strip the phenomenon to its dynamical essence, and will, for example, have nothing to say about drumlin stratigraphy.

\section{Stability of bedforms}

To a dynamicist, the most obvious source of explanation for drumlins, such as those shown in figures 1 and 2, is that they represent the evolved form of an instability. The image in figure 2 is suggestive of an evolved instability generated by local variations in topography. Drumlins (rock-cored or not) are formed of till (figure 3), and the basic dynamical explanation is that a uniform layer of subglacial till is unsta- 
ble. Fluid mechanics abounds with such spatial instabilities, and the idea that the basic instability can lead, under different circumstances, to Rogen moraine, drumlins or megaflutes, carries little in the way of surprise. (Rogen moraine consists of semi-regular washboard-like ridges of till aligned transverse to the ice flow.) If a uniform till layer is unstable, it is natural to expect a transition, as a critical parameter changes, from a stable state (no bedforms) to two-dimensional waves (Rogen moraine), which are themselves transversely unstable (drumlins), leading in extreme conditions to megaflutes. Indeed, such ideas have already been more or less expressed (Menzies and Shilts 1996, Lundqvist 1989). Such sequences of transitions are very familiar in convection (Busse 1978), shear flow (Maslowe 1985), and more germanely in fluvial erosion forms (Richards 1982), and the analogy between drumlins and fluvial dunes is of long standing (Kinahan and Close 1872, and particularly Davis 1884). More controversial is the origin of the instability. The flood theory of Shaw assumes that bedforms (particularly drumlins) occur through subglacial floods. We do not examine this possibility further. The deformation theory assumes that the instability is analogous to fluvial bedforms (in the sense that dunes are caused by the interaction of an overlying shear flow with an erodible and mobile substrate), but is due to the ice flow. Our purpose in this paper is to show that such an instability does in fact exist, and thereby elucidate what the primary controlling mechanics are. The model presented here is essentially due to Hindmarsh (1998a, 1998b), who showed that the classical Nye-Kamb sliding theory allied with basal till deformation would produce instability in many cases. Hindmarsh used a viscous till rheology, but the resulting algebraic complication prevented him from deriving concise criteria for instability. Our purpose here is thus to derive analytic criteria for Hindmarsh's instability.

The starting point of the theory is the observation of Hindmarsh $(1996,1998 \mathrm{~b})$ that a layer of till of thickness $s$ depending, let us say, on one (flow-line) spatial direction $x$, satisfies an evolution equation of the form

$$
s_{t}+q_{x}=0,
$$

where subscripts denote partial derivatives, $t$ is time, and $q$ is the till flux. This equation neglects erosion or deposition rates, which would be represented by sink or 
source terms on the right hand side.

Evidently the till flux $q$ will depend on the till thickness $s$ and also the basal shear stress $\tau$. The dependence is mediated by the till rheology, and while there are different possibilities for this (Boulton and Hindmarsh 1987, Kamb 1991, Hooke et al. 1997), it seems clear that till flow decreases as the effective pressure $p_{e}$, defined as the difference between the confining pressure and the pore water pressure $p_{w}$, increases.

We will suppose for simplicity that the till layer rests on a flat substrate, e.g. bedrock. (More generally, bedrock irregularities will promote the instability we discuss, and figure 2 may be suggestive of this.) If the till layer is perturbed to have variable thickness, then as the ice flows over a protuberance (where $s$ is larger), the overburden normal stress will increase. This causes an increase in $p_{e}$ and thus a decrease in till flow. In turn, this can cause the till to stall and further enhance the growth of $s$. It is this feedback between growth of $s$ and increased normal stress in the ice which causes instability (Hindmarsh 1998a).

\section{Subglacial bedforms}

We now consider two-dimensional flow of an ice sheet over a deformable substrate, as illustrated in figure 4 . We take the vertical axis to be $z$, with $z=0$ defining the ice-till interface in the uniform reference state, and we suppose that $z=-\bar{s}$ represents the (flat) base of the deforming till, whether this be bedrock or immobile till (Boulton 1987), and the ice surface is at $z=z_{i}$.

\section{Effective pressure}

Within the till, we let $p_{s}$ be the average pressure within the solid phase, and $p_{w}$ is the volume averaged pore water pressure. The total confining pressure within the till is therefore

$$
P=(1-n) p_{s}+n p_{w}
$$

where $n$ is the porosity, and Terzaghi's effective pressure is then defined (see Bear and Bachmat 1990, pp. 153ff., for a lucid discussion) by

$$
p_{e}=P-p_{w}=(1-n)\left(p_{s}-p_{w}\right)
$$


Crucial to the determination of till velocity is the effective pressure at the ice-till interface, denoted by $N$, and defined as $-\sigma_{n n}-p_{w}$, where $-\sigma_{n n}$ is ice normal stress at the ice-till interface, and $p_{w}$ is pore water pressure.

Consider first a uniform shearing flow of ice of thickness $z_{i}$ over a layer of till of thickness $\bar{s}$ (we avoid the complication that in an ice sheet there is a small but crucially non-zero surface slope). In this reference state, the ice pressure is

$$
p_{i}=p_{a}+\rho_{i} g\left(z_{i}-z\right)
$$

where $p_{a}$ is atmospheric pressure, $\rho_{i}$ is ice pressure, and $g$ is the acceleration due to gravity. If the pore pressure $p_{w}$ is equal to the pressure $p_{c}$ of a supposed channelised drainage system, then the interfacial effective pressure is given by

$$
\bar{N}=p_{a}+\rho_{i} g z_{i}-p_{c}
$$

Now consider the more general situation shown in figure 4 where the ice-till interface is at $z=z_{b}$. The ice flows over the irregular bed, and this generates non-cryostatic pressure and normal stresses at the bed. If we define the reduced pressure $\Pi$ by

$$
p_{i}=p_{a}+\rho_{i} g\left(z_{i}-z\right)+\Pi
$$

and let $\tau_{n n}$ be the deviatoric stress in the ice normal to the interface, then the effective pressure at the interface is given by

$$
N=\bar{N}+\Delta \rho_{w i} g z_{b}+\Pi-\tau_{n n},
$$

where

$$
\Delta \rho_{w i}=\rho_{w}-\rho_{i}
$$

$\rho_{w}$ is the density of water, and we suppose that the hydraulic potential within the till is constant and equal to the drainage channel pressure, i.e.

$$
p_{w}+\rho_{w} g z=p_{c}
$$

The drainage effective pressure $\bar{N}$ is assumed to be determined via a subglacial drainage theory such as that of Walder and Fowler (1994), and will be assumed to be constant in this study. 
Below $z_{b}$, we suppose that the till and pore water pressures increase hydrostatically, and thus

$$
p_{e}=N+(1-n) \Delta \rho_{s w} g\left(z_{b}-z\right),
$$

where

$$
\Delta \rho_{s w}=\rho_{s}-\rho_{w},
$$

and $\rho_{s}$ is the density of sediments.

\section{Till rheology}

To determine the till velocity, we must choose a rheology for till. The conceptual candidates are a viscous law (Boulton and Hindmarsh 1987), a plastic failure law (Kamb 1991, Iverson et al. 1998), or some more convoluted generalisation (Clarke 1987). In addition, sliding probably occurs at ice-till and till-bed interfaces, the latter promoting erosion. Partly because our purpose is didactic, we select a viscous rheology. As pointed out by Boulton (1996), the plastic rheology can be accommodated within this framework by an appropriate parametric limit. This is discussed further in appendix A.

We suppose that the shear rate of till is

$$
\frac{\partial v}{\partial z}=A \exp \left(\alpha \tau / p_{e}\right),
$$

where $\tau$ is the shear stress, $v$ is the horizontal till velocity, and we suppose that $\alpha$ is large. This is essentially Kamb's (1991) choice, and is promoted by Mitchell (1993, pp. 359 ff.); but it can also be related in a practical sense to Boulton and Hindmarsh's (1987) one (see appendix A).

We use (10), and denote $z_{b}-z=\zeta$, so that

$$
\begin{aligned}
-\frac{\partial v}{\partial \zeta} & =A \exp \left[\frac{\alpha \tau}{N+\Delta \rho_{s w} g(1-n) \zeta}\right] \\
& \approx A^{*} \exp \left(-\zeta / \zeta^{*}\right)
\end{aligned}
$$

where

$$
\begin{aligned}
A^{*} & =A \exp \left(\frac{\alpha \tau}{N}\right), \\
\zeta^{*} & =\frac{N^{2}}{\alpha \tau \Delta \rho_{s w} g(1-n)},
\end{aligned}
$$


using the assumption that $\zeta \ll \alpha \tau \zeta^{*} / N$ (mainly for algebraic convenience). Assume that at the till-bed interface, slip does not occur, that is, $v=0$ at $\zeta=s$. If, in addition, slip does not occur at the ice-till interface, then $v=u$ at $\zeta=0$, where $u$ is the basal ice velocity, and

$$
u-v=A^{*} \zeta^{*}\left[1-e^{-\zeta / \zeta^{*}}\right]
$$

whence

$$
u=A^{*} \zeta^{*}\left[1-e^{-s / \zeta^{*}}\right]
$$

and thus the till flux $q=\int_{0}^{s} v d \zeta$ is given by

$$
q=A^{*} \zeta^{* 2}\left[1-\left(1+\frac{s}{\zeta^{*}}\right) e^{-s / \zeta^{*}}\right]
$$

Figure 5 shows a sequence of graphs of $q$ as a function of $s$ with $\alpha=10$, for various values of $\tau$. It can be seen that $q$ is an increasing function of $s$, and also generally increases with $\tau$, except at low stresses and high till thicknesses. Figure 6 shows the basal ice velocity computed for the same parameter values. Note that $u$ also increases with both $\tau$ and $s$, except at low stresses and high till thicknesses.

Till conservation is expressed by the equation (1), where we ignore the small effects of basement erosion and depositional lodgement from the overlying ice.

\section{Basal sliding}

The basic mechanism for the instability we shall discuss is the following. If a uniform layer of till is perturbed (for example by a bedrock knoll), then the flow of the ice over the bump causes an excess normal stress on it, and hence an increased effective pressure at the ice-till interface. Since the till flux (figure 5) is generally increasing with $\tau$ and thus decreasing with $N$, this causes a slowing down and thus accumulation of the till. In order to model this stability mechanism, we need to describe the deformational flow of the ice, essentially using the theory of basal sliding.

The classical theory of sliding was initiated by Weertman (1957), and developed principally by Nye $(1969,1970)$ and Kamb (1970). This is the form of the theory we use here (see also Hindmarsh 1998a). We ignore regelation and consider the slow flow of ice over the basal till layer; we take the ice viscosity $\mu$ to be constant. In the 
uniform (undisturbed) state, with the ice-till interface at $z=0$, a steady shearing flow in the basal ice due to an imposed basal shear stress $\bar{\tau}$ is $(\bar{u}+\bar{\tau} z / \mu, 0)$, where the cartesian coordinates are $(x, z)$. In the theory presented here, we will suppose that the ice depth is very large, so that this velocity field is obtained far from the bed. The assumption of large depth is valid provided the wavelength of basal undulations is much less than the depth, and for drumlins this may not be highly accurate. We follow the assumption here for simplicity in exposition, and also because the instability we find does not rely on having a finite ice depth. In classical parlance, $\bar{\tau}$ is the basal shear stress and $\bar{u}$ is the effective sliding velocity. Sliding theory thus computes $\bar{\tau}$ as a function of $\bar{u}$ and other variables. (Notice that the uniform basic state is a shearing flow, which is not the case in classical sliding theory (Nye 1969).)

In terms of a stream function $\psi$ (so the ice velocity is $\left(\psi_{z},-\psi_{x}\right)$ ), we have

$$
\psi \sim \bar{u} z+\frac{\bar{\tau}}{2 \mu} z^{2} \quad \text { as } \quad z \rightarrow \infty
$$

We define the reduced pressure $\Pi$ via (6), so that

$$
\begin{aligned}
& \Pi_{x}=\mu \nabla^{2} \psi_{z}, \\
& \Pi_{z}=-\mu \nabla^{2} \psi_{x},
\end{aligned}
$$

with

$$
\Pi \rightarrow 0 \quad \text { as } \quad z \rightarrow \infty
$$

At the ice-till interface $z=z_{b}$, we define the deviatoric shear stress to be $\tau$, the deviatoric normal stress is $\tau_{n n}$, and the tangential velocity (taken as continuous across the interface) is $u$, which we take to be given by (16). In terms of $\psi$, we have

$$
\begin{aligned}
-\tau_{n n} & =\frac{2 \mu}{1+s_{x}^{2}}\left[\left(1-s_{x}^{2}\right) \psi_{x z}+s_{x}\left(\psi_{z z}-\psi_{x x}\right)\right] \\
\tau & =\frac{\mu}{1+s_{x}^{2}}\left[\left(1-s_{x}^{2}\right)\left(\psi_{z z}-\psi_{x x}\right)-4 s_{x} \psi_{x z}\right] .
\end{aligned}
$$

Lastly, continuity of velocity at the interface implies

$$
\begin{aligned}
\psi_{z} & =u \\
\psi_{x}+s_{t}+u s_{x} & =0
\end{aligned}
$$


In order to see that the model is sensibly posed, we can argue as follows. $\psi$ satisfies

$$
\nabla^{4} \psi=0
$$

and requires two boundary conditions on each of $z=s$ and $z \rightarrow \infty$. As $z \rightarrow \infty$, (18) is equivalent to two conditions, and also serves to determine $\bar{\tau}$ in terms of $\bar{u}$. The equation (1) determines $s$ in principle, while (16) determines $u$. (22) then provide the two basal boundary conditions for $\psi$, while (21) serves to determine $\tau$ and $N$, which are involved in the determination of $q$ and $u$. Of course, the boundary conditions do not actually uncouple in this way, but this way of thinking helps to show that the problem has the right number of boundary conditions.

\section{Linear stability analysis}

The basic uniform state is that of a shear flow over a horizontal ice-till base at $z=0$, and an underlying till layer of uniform thickness $\bar{s}$. We denote uniform state variables with an overbar, and consider perturbations to this state by writing

$$
\psi=\bar{u} z+\frac{\bar{\tau}}{2 \mu} z^{2}+\Psi
$$

We linearise about the basic solution $\Psi=0, s=\bar{s}, u=\bar{u}, \tau=\bar{\tau}$, on the basis that $s_{x} \ll 1$. We then have

$$
\begin{aligned}
& \Pi_{x}=\mu \nabla^{2} \Psi_{z} \\
& \Pi_{z}=-\mu \nabla^{2} \Psi_{x}
\end{aligned}
$$

with

$$
\Pi, \Psi \rightarrow 0 \quad \text { as } \quad z \rightarrow \infty
$$

and

$$
\begin{aligned}
\Psi_{z} & \approx u-\bar{u} \\
-\Psi_{x} & \approx s_{t}+\bar{u} s_{x} \\
\tau-\bar{\tau} & \approx \mu\left(\Psi_{z z}-\Psi_{x x}\right) \\
N & \approx \bar{N}+\Delta \rho_{w i} g(s-\bar{s})+\Pi+2 \mu \Psi_{x z}+2 \bar{\tau} s_{x}
\end{aligned}
$$


on $z=0$, approximately. For a mode of wavenumber $k, \Psi$ is given by

$$
\Psi=(a+b z) e^{-k z} e^{i k x+\sigma t}
$$

whence

$$
\Pi=-2 \mu i k b e^{-k z} e^{i k x+\sigma t}
$$

and if

$$
\begin{aligned}
u & =\bar{u}+\tilde{u} e^{i k x+\sigma t} \\
\tau & =\bar{\tau}+\tilde{\tau} e^{i k x+\sigma t} \\
s & =\bar{s}+\tilde{s} e^{i k x+\sigma t} \\
N & =\bar{N}+\tilde{N} e^{i k x+\sigma t}
\end{aligned}
$$

then the boundary conditions (27) give

$$
\begin{aligned}
b-k a & =\tilde{u} \\
-i k a & =(\sigma+i k \bar{u}) \tilde{s} \\
\tilde{\tau} & =-2 k \mu \tilde{u} \\
\tilde{N} & =-2 \mu i k^{2} a+\left(\Delta \rho_{w i} g+2 i k \bar{\tau}\right) \tilde{s}
\end{aligned}
$$

If we write the first term in $(31)_{4}$ in terms of $\tilde{s}$, then we can see that the relative sizes of the three terms in that equation are $2 \mu k^{2} u, \Delta \rho_{w i} g$ and $2 k \tau$. If we use values $\mu \sim 6$ bar $\mathrm{y}, u \sim 100 \mathrm{~m} \mathrm{y}^{-1}, \Delta \rho_{w i} \sim 10^{2} \mathrm{~kg} \mathrm{~m}^{-3}, g \sim 10 \mathrm{~m} \mathrm{~s}^{-2}, \tau \sim 0.2$ bar and anticipating $k \sim 10^{-2} \mathrm{~m}^{-1}$ (as a representative drumlin wave number), then the corresponding estimates in units of bar $\mathrm{m}^{-1}$ are $0.12,0.01$, and 0.004 . On this basis we neglect the second and third terms in $(31)_{4}$. Strictly, this neglect is invalid when $k$ is very small, but this is of no significance, as we shall find that in that case the growth rate of unstable modes becomes very small. The basal ice velocity $u(s, \tau, N)$ is expanded as

$$
\tilde{u}=u_{s} \tilde{s}+u_{\tau} \tilde{\tau}+u_{N} \tilde{N}
$$

where $u_{s}=\partial u / \partial s$, evaluated at $s=\bar{s}, \tau=\bar{\tau}$ and $N=\bar{N}$, and similarly if we define the perturbed till flux via $q=\bar{q}+\tilde{q} e^{i k x+\sigma t}$, then

$$
\tilde{q}=q_{s} \tilde{s}+q_{\tau} \tilde{\tau}+q_{N} \tilde{N}
$$


Finally, linearisation of (1) gives the recipe for the eigenvalue $\sigma$ as

$$
\sigma \tilde{s}+i k \tilde{q}=0
$$

The equations (31-34) provide seven relations for $a, b, \tilde{u}, \tilde{s}, \tilde{\tau}, \tilde{N}, \tilde{q}$ and $\sigma$. To simplify them, it is easiest to first use $(31)_{2}$ to write $\tilde{s}$ in terms of $a$, then combine (33) and (34) to eliminate $\tilde{q}$. (32) and the modified (33) then provide two homogeneous equations for $a$ and $\tilde{u}$, when $\tilde{s}, \tilde{\tau}$ and $\tilde{N}$ are written in terms of them. Cross multiplication then yields an expression for $\sigma$ in the form

$$
\sigma=\rho-i k c
$$

where $\rho$ is the growth rate and $c$ is the wave speed, and these are given by

$$
\rho=\frac{2 \mu k^{3} \Delta_{1} \Delta_{2}}{\left(1+2 \mu k u_{\tau}\right)^{2}+4 \mu^{2} k^{4} \Delta_{2}^{2}}
$$

and

$$
c=\bar{u}-\frac{\Delta_{1}\left(1+2 \mu k u_{\tau}\right)}{\left(1+2 \mu k u_{\tau}\right)^{2}+4 \mu^{2} k^{4} \Delta_{2}^{2}}
$$

where

$$
\begin{aligned}
& \Delta_{1}=\left(1+2 \mu k u_{\tau}\right)\left(\bar{u}-q_{s}\right)+2 \mu k q_{\tau} u_{s}, \\
& \Delta_{2}=q_{N}+2 \mu k\left(u_{\tau} q_{N}-q_{\tau} u_{N}\right) .
\end{aligned}
$$

Note that the ice normal stress effect on $N$ is manifested by the term $-2 \mu i k^{2} a$ in $(31)_{4}$, and the effect of ignoring this is equivalent to putting $u_{N}$ and $q_{N}$ to zero, in which case $\Delta_{2}=0$ and thus the bed is neutrally stable. The ice normal stress effect is thus the mechanism for instability.

So far, no specific assumptions about the till flux and velocity have been used. Now we use the explicit expressions given by (16) and (17) in order to evaluate $\Delta_{1}$ and $\Delta_{2}$ explicitly; thus

$$
\begin{aligned}
u & =A^{*} \zeta^{*}\left(1-e^{-X}\right) \\
q & =A^{*} \zeta^{* 2}\left[1-(1+X) e^{-X}\right]
\end{aligned}
$$

where

$$
X=s / \zeta^{*}, \quad \zeta^{*}=\frac{N^{2}}{\alpha \tau \Delta \rho_{s w} g(1-n)}, \quad A^{*}=A \exp (\alpha \tau / N)
$$


Define

$$
U(X)=1-e^{-X}, \quad W(X)=1-(1+X) e^{-X}
$$

after some algebra which is outlined in appendix B, we find that the critical stability parameters $\Delta_{1}$ and $\Delta_{2}$ (defined in (38)) are given by

$$
\begin{aligned}
& \Delta_{1}=A^{*} \zeta^{*} W\left[1+\frac{2 \mu k A^{*} \zeta^{*}}{\tau}\left\{\frac{\alpha \tau}{N}-F(X)\right\}\right], \\
& \Delta_{2}=\frac{q}{N}\left[-\frac{\alpha \tau}{N}+4 Q(X)+\frac{2 \alpha \mu k A^{*} \zeta^{*}}{N} J(X)\right],
\end{aligned}
$$

where (using $W^{\prime}=U-W$ and $U^{\prime}+U=1$ )

$$
\begin{aligned}
Q(X) & =1-\frac{X W^{\prime}}{2 W} \\
J(X) & =U\left[1+X\left(\frac{U^{\prime}}{U}-\frac{W^{\prime}}{W}\right)\right] \\
F(X) & =\frac{U W+2 W U^{\prime}-X U U^{\prime}}{W}
\end{aligned}
$$

and the variables are evaluated at the basic state. The functions $J$ and $Q$ increase monotonically from 0 to 1 , and are displayed in figure 7 . The function $F(X)$ is well approximated by $1-e^{-0.7 X}$, and is shown in figure 8 . Explicit definitions of the functions are given in appendix B.

Clearly, instability occurs if $\Delta_{1} \Delta_{2}>0$. In practice, using typical values $\mu \sim 6$ bar $\mathrm{y}, u \sim A^{*} \zeta^{*} \sim 100 \mathrm{~m} \mathrm{y}^{-1}, \tau \sim 0.2$ bar, $N \sim 1$ bar, $\alpha \sim 10$, and anticipating drumlin wavenumbers $k \sim 0.01 \mathrm{~m}^{-1}$ (corresponding to wavelengths $2 \pi / k \sim 600 \mathrm{~m}$ ), we find $2 \mu k u / \tau \sim 60,2 \alpha \mu k u / N \sim 30$, and these large values suggest that typically $\Delta_{2}>0$, so that the instability criterion is essentially that

$$
\frac{\alpha \tau}{N} \gtrsim F(X)
$$

We elaborate on this instability criterion in the following section.

\section{Discussion}

We define the dimensionless wave number parameter $K$ by

$$
K=\frac{2 \mu \alpha A k}{r}
$$


where

$$
r=\Delta \rho_{s w} g(1-n) \approx 0.1 \text { bar }^{-1}
$$

and the dimensionless stress $Y$ by

$$
Y=\frac{\alpha \tau}{N}
$$

Using the definitions of $A^{*}$ and $\zeta^{*}$ in (40), we have that the stability parameters $\Delta_{1}$ and $\Delta_{2}$ are given by

$$
\begin{aligned}
& \Delta_{1}=A^{*} \zeta^{*} W(X)\left\{1+\frac{K e^{Y}}{Y^{2}}[Y-F(X)]\right\}, \\
& \Delta_{2}=\frac{q}{N}\left\{-Y+4 Q(X)+\frac{K e^{Y}}{Y^{2}} J(X)\right\} .
\end{aligned}
$$

Using the values above (44), we have $K \approx 120$, and we will suppose that $K$ is large. The critical curves $\Delta_{1}=0$ and $\Delta_{2}=0$ are thus given by

$$
\begin{aligned}
\left(\Delta_{1}\right): \quad Y & =F(X)+O\left(\frac{1}{K}\right) \\
\left(\Delta_{2}\right): \quad X & =\sqrt{\frac{6}{K}} Y e^{-Y / 2}+O\left(\frac{1}{K}\right),
\end{aligned}
$$

where for the latter we use the small $X$ approximations $Q \approx \frac{1}{3} X, J \approx \frac{1}{6} X^{2}$. The corresponding graphs are plotted in figure 9.

The region of instability lies between the two curves. A sufficient condition for instability is that

$$
X=\frac{\alpha r \tau s}{N^{2}} \gtrsim\left(\frac{24}{K}\right)^{1 / 2} e^{-1} \approx \frac{1.8}{\sqrt{K}}, \quad Y=\frac{\alpha \tau}{N} \gtrsim 1,
$$

as these values delineate the $X$ and $Y$ maxima of the two curves in figure 9 . The practical implications are discussed in the conclusions.

\section{Growth rate}

The growth rate $\rho$ is given by (36). In terms of $X, Y$, and $K$, we find

$$
2 \mu k u_{\tau}=\frac{K e^{Y}}{Y^{2}}[U Y-W]
$$

Using this together with (48) and assuming that $K$ is large, we derive the approximate expression for $\rho$,

$$
\rho \approx\left(\frac{A N}{2 \mu}\right)^{1 / 2}\left[\frac{D\left(k / k^{*}\right)^{3}}{B^{2}+C^{2}\left(k / k^{*}\right)^{4}}\right]
$$


where

$$
k^{*}=\frac{r}{(2 \mu A N)^{1 / 2}}
$$

and

$$
\begin{aligned}
D(X, Y) & =Y W^{2}(X) J(X)[Y-F(X)] \\
B(X, Y) & =Y^{2} e^{-Y}[U(X) Y-W(X)] \\
C(X) & =W(X) J(X) .
\end{aligned}
$$

These are $O(1)$ functions, and are shown in figure 10. For example, with values

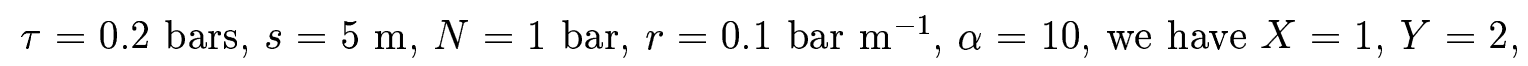
whence $D=0.025, C=0.032, B=0.54$. We see that the growth rate tends to zero as $k \rightarrow 0$ and $k \rightarrow \infty$, and has a maximum at

$$
k=k_{\max }=3^{1 / 4} \sqrt{\frac{B}{C}} k^{*},
$$

and this is $5.4 k^{*}$ for $X=1, Y=2$. Clearly $k^{*-1}$ is a distinguishing length scale, as we would expect instabilities to occur at finite amplitude where the growth rate is largest. For values $\mu \sim 6$ bar y, $A \sim 10 \mathrm{y}^{-1}, N \sim 1$ bar, $r \sim 0.1$ bar $^{-1}$, the length scale is $100 \mathrm{~m}$, and the preferred wavelength of instability would be $2 \pi / k_{\max } \approx 116$ m. It is clear from the variation of $C$ in figure 10 that higher values of $X$ give higher wavelengths. From (52), the time scale for growth is $2 \mu / A N$, and with the above values, this is a year.

The explicit formula for the maximum growth rate is

$$
\rho_{\max }=\left(\frac{A N}{2 \mu}\right)^{1 / 2}\left(\frac{3^{3 / 4} D}{4 B^{1 / 2} C^{3 / 2}}\right),
$$

and this is plotted in figure 11. Note that the plot shows $\rho_{\max }$ for values $X>0.5$. The approximation in (52) breaks down as $X \rightarrow 0$, and in fact the uniform state becomes stable again.

The wavelength of the most rapidly growing mode is given by

$$
L=\frac{2 \pi}{3^{1 / 4}} \sqrt{\frac{C}{B}} k^{*-1},
$$

and this is shown in figure 12 for $X>0.5$ in the unstable region. We see that for our typical value $k^{*-1}=100 \mathrm{~m}$, the preferred wavelengths lie in the range 100-1000 
m (the higher values near the stability threshold correspond to very slowly growing modes).

\section{Wave speed}

Using the same approximations as above, the wave speed of the perturbations is

$$
c=u-u^{*}\left\{\frac{B D}{C\left[B^{2}+C^{2}\left(k / k^{*}\right)^{4}\right]}\right\},
$$

where the velocity scale is

$$
u^{*}=\frac{A N}{r} .
$$

With preceding values, we have $u^{*} \sim 100 \mathrm{~m} \mathrm{y}^{-1}$, and the migration speed relative to the basal ice flow is of similar size to it. Since $Y>F$ for instability, and $W / U<F$ (in fact they are almost equal), then $B>0$ when $\rho>0$, and the wave speed is less than that of the ice.

In fact, we see from (39) that

$$
u=u^{*} \frac{e^{Y}}{Y} U
$$

and therefore the wave speed at the wavenumber $k_{\max }$ of maximum growth in (55) is

$$
c=u^{*} V(X, Y)
$$

where

$$
V(X, Y)=\frac{e^{Y} U}{Y}-\frac{D}{4 B C} .
$$

Figure 13 plots the wave speed of the most rapidly growing mode as a function of $X$ and $Y$. These drumlins always move downstream, at a rate which is slightly less than the basal ice speed.

\section{Conclusions}

We have shown explicitly that Hindmarsh's (1998a) mechanism for the generation of bedform will realistically occur under ice sheets, given favourable conditions. Several preconditions must be met for the instability to occur. There must be a till layer; the basal ice must be at the melting point, and the resulting drainage pressure must 
be high, and presumably associated with a distributed drainage system. However, if it is too high, we might expect rapid sliding and therefore very low shear stresses, which mitigates against instability. Thus while the instability seems certainly to be accessible in general, conflicting external parameters may prevent it occurring; and indeed, drumlins do not occur everywhere.

Hindmarsh (1998a) found instability for many different sets of parameter values. Although our result here is based on a slightly different till rheology, the results should be comparable. The simplest presentation of the stability map in figure 9 is if we define

$$
\xi=\frac{r s}{N}
$$

so that $X=Y \xi$, and the instability region lies between the two curves $Y \approx F(Y \xi)$ and $\xi \approx(6 / K)^{1 / 2} e^{-Y / 2}$, as shown in figure 14. Drumlin forming instability is caused in this model by high basal shear stress, $\tau>N / \alpha$, and is likely to occur in practice if the till has a strong rate dependence on shear stress, and if, additionally, the effective pressure is low. This may be the case for a distributed drainage system as for example under ice stream B, but for high values $N>10$ bars appropriate to channelised drainage systems, instability is unlikely to occur (and indeed the till would be unlikely to deform).

We have found that the instability operates on the convective time scale, which is on the order of years; drumlins form rapidly. The instability has preferred wavelengths in the range 100-1000 m, comparing favourably to observations, though this depends on our choice of values for $A$ and $N$. Like fluvial dunes, these drumlins move downstream, but unlike dunes, the wave speed is comparable to the ice speed.

An interesting feature of figure 14 is that it predicts instability independently of basal shear stress if the till thickness is between upper and lower limits of $1.5 \mathrm{~N} / \mathrm{r}$ and $0.22 N / r$ (if $K=120$ ). It is tempting to suppose that in this case drumlins might form from thickening till until they reach a sufficient thickness that they stabilise; however, examination of this possibility awaits the development of a nonlinear theory (cf. Hindmarsh 1998b).

The theory advanced here does not preclude the possibility of other mechanisms, however those that have been promoted in the literature tend not to be built on sound 
mechanical principles. A recent example is the suggestion by Kleman and Hattestrand (1999) that Rogen moraine patterns occur when till accumulations at the boundary between frozen and temperate basal ice are fractured. This notion sounds plausible even if hypothetical, but it is based on the underlying assumption that till accumulates at the frozen-temperate boundary because of the stress accumulation there as the ice switches from a no slip to a sliding basal boundary condition. This purely theoretical idea, based on an analysis of Hutter and Olunloyo (1982), is apparently not applicable to the frozen-temperate boundary when account is taken of realistic dependence of basal sliding on the temperature field (see Fowler and Larson 1980, page 338).

In conclusion, drumlins most obviously represent the evolution of an instability, initially of transverse form (as in Rogen moraine), and this instability can be potentially explained via the interaction of ice flow and till flow. We expect these transverse waves to be susceptible to three-dimensional instabilities, in common with other similar wave transitions, for example fluvial dunes, and we have shown that Hindmarsh's (1998a) model can explain their initial evolution.

I thank Wendy Everett for correspondence and information concerning the early drumlin literature, and Felix Ng for his ever-vigilant perusal of the manuscript. I am indebted to Christian Schoof for spotting an error in an earlier version of the paper.

\section{Appendix A}

\section{Till rheology}

Till is a complex medium and, insofar as it is analogous to soil in its rheological behaviour, it can be expected that a detailed realistic description of it should include such phenomena as irreversible elasticity, secondary creep, failure, dilatation, effect of fabrics, and so on (Clarke 1987, Mitchell 1993). In selecting the simple viscous rheology in (12), we are partly motivated by the wish for simplicity, but also by the realistic hope that when considering long term strain in steady deformation, many of the above-mentioned phenomena may be practically irrelevant.

There has been much discussion in the literature (e.g. Hooke et al. 1997, Kamb 1991, Iverson et al. 1998) of whether an appropriate long-term rheology for till is a 
rigid-plastic one or a viscous one. Our point of view here is that the two choices can simply be viewed as representing different parametric limits, and are not conceptually distinct. Furthermore, we do not wish to be overly swayed by laboratory experiments where scaling up issues may be important.

The analogy between a power law rheology and the exponential rate law (12) can be drawn as follows. Define $\mu^{*}$ by

$$
A=\varepsilon_{\text {obs }} \exp \left(-\alpha \mu^{*}\right)
$$

where $\varepsilon_{\text {obs }}$ is a typical observed ice shear strain rate, so that

$$
\frac{\partial v}{\partial z}=\varepsilon_{\text {obs }} \exp \left[\frac{\alpha}{p_{e}}\left\{\tau-\mu^{*} p_{e}\right\}\right]
$$

and $\mu^{*} p_{e}$ is essentially a yield stress, with $\partial v / \partial z \ll U / d$ for $\tau<\mu^{*} p_{e}$. If we suppose $\left(\tau-\mu^{*} p_{e}\right) / \mu^{*} p_{e}$ is small (this is not a restriction if $\alpha$ is large, and if $\alpha$ is $O(1)$, then the exponential and power law rheologies are similar anyhow), (A.2) is equivalent to

$$
\begin{aligned}
\frac{\partial v}{\partial z} & \approx \varepsilon_{\text {obs }} \exp \left[\mu^{*} \alpha \ln \left(1+\frac{\tau-\mu^{*} p_{e}}{\mu^{*} p_{e}}\right)\right] \\
& =\varepsilon_{\text {obs }}\left(\frac{\tau}{\mu^{*} p_{e}}\right)^{\mu^{*} \alpha}
\end{aligned}
$$

which is one version of the Boulton-Hindmarsh rheology.

\section{Appendix B}

In calculating the partial derivatives of $u$ and $q$, it is convenient to use the definition of the dimensionless stress, $Y=\alpha \tau / N$, given in (47). Then we have

$$
A^{*}=A e^{Y}, \quad \zeta^{*}=\frac{N}{r Y}
$$

where $r$ is a constant given in (46), and the partial derivatives of $A^{*}, \zeta^{*}$ and $X$ are given by

$$
\begin{aligned}
& \frac{A_{\tau}^{*}}{A^{*}}=\frac{Y}{\tau}, \quad \frac{\zeta_{\tau}^{*}}{\zeta^{*}}=-\frac{1}{\tau}, \quad \frac{A_{N}^{*}}{A^{*}}=-\frac{Y}{N}, \quad \frac{\zeta_{N}^{*}}{\zeta^{*}}=\frac{2}{N}, \\
& \frac{X_{\tau}}{X}=\frac{1}{\tau}, \quad \frac{X_{N}}{X}=-\frac{2}{N}, \quad \frac{X_{s}}{X}=\frac{1}{s} .
\end{aligned}
$$


Since

$$
u=A^{*} \zeta^{*} U(X), \quad q=A^{*} \zeta^{* 2} W(X)=A^{*} \zeta^{*} s W / X
$$

we find

$$
\begin{array}{r}
\frac{u_{\tau}}{u}=\frac{1}{\tau}\left[Y-1+\frac{X U^{\prime}}{U}\right], \\
\frac{q_{\tau}}{q}=\frac{1}{\tau}\left[Y-2+\frac{X W^{\prime}}{W}\right], \\
\frac{u_{N}}{u}=\frac{1}{N}\left[-Y+2-2 \frac{X U^{\prime}}{U}\right], \\
\frac{q_{N}}{q}=\frac{1}{N}\left[-Y+4-2 \frac{X W^{\prime}}{W}\right], \\
\frac{u_{s}}{u}=\frac{X U^{\prime}}{s U}, \quad \frac{q_{s}}{q}=\frac{X W^{\prime}}{s W} .
\end{array}
$$

From these we find, using $U-W^{\prime}=W$,

$$
u-q_{s}=A^{*} \zeta^{*} W
$$

and the definitions of $\Delta_{1}$ and $\Delta_{2}$ in the text follow on substituting the expressions in (B.4) into (38).

The instability functions defined in (43) are given explicitly by the following expressions, using the definitions of $U$ and $W$ in (41):

$$
\begin{aligned}
Q(X) & =\frac{1-\left(1+X+\frac{1}{2} X^{2}\right) e^{-X}}{1-(1+X) e^{-X}} \\
J(X) & =\frac{1-\left(2+X^{2}\right) e^{-X}+e^{-2 X}}{1-(1+X) e^{-X}} \\
F(X) & =\frac{1-2 X e^{-X}-e^{-2 X}}{1-(1+X) e^{-X}}
\end{aligned}
$$

\section{References}

Bear, J. and Y. Bachmat 1990 Introduction to modeling of transport phenomena. Kluwer, Dordrecht.

Boulton, G.S. 1987 A theory of drumlin formation by subglacial sediment deformation. In Drumlin Symposium, eds. J. Menzies and J. Rose, Balkema, Rotterdam, pp. 25-80. 
Boulton, G.S. 1996 Theory of glacial erosion, transport and deposition as a consequence of subglacial sediment deformation. Journal of Glaciology 42, 43-62.

Boulton, G.S. and R.C.A. Hindmarsh 1987 Sediment deformation beneath glaciers: rheology and geological consequences. Journal of Geophysical Research 92, 9,059-9,082.

Boyce, J.I. and N. Eyles 1991 Drumlins carved by deforming till streams below the Laurentide ice sheet. Geology 19, 787-790.

Busse, F.H. 1978 Nonlinear properties of convection. Reports of Progress on Physics 41, 1,929-1,967.

Clarke, G.K.C. 1987 Subglacial till: a physical framework for its properties and processes. Journal of Geophysical Research 92, 9,023-9,036.

Davis, W. M. 1884 The distribution and origin of drumlins. American Journal of Science 23, 407-416.

Embleton, C. and C.A.M. King 1975 Glacial geomorphology. Edward Arnold, London.

Everett, W. 1987 An analysis of the literature on drumlins and related streamlined forms. M. Phil. thesis, University of London, $491 \mathrm{pp}$.

Fowler, A. C. and D. A. Larson 1980 The uniqueness of steady state flows of glaciers and ice sheets. Geophysical Journal of the Royal Astronomical Society 63, 333345.

Gravenor, C.P. 1953 The origin of drumlins. American Journal of Science 251, $674-681$.

Hindmarsh, R.C.A. 1996 Sliding of till over bedrock: scratching, polishing, comminution and kinematic wave theory. Annals of Glaciology 22, 41-48.

Hindmarsh, R.C.A. 1998a The stability of a viscous till sheet coupled with ice flow, considered at wavelengths less than the ice thickness. Journal of Glaciology 44, 285-292. 
Hindmarsh, R.C.A. 1998b Drumlinisation and drumlin-forming instabilities: viscous till mechanisms. Journal of Glaciology 44, 293-314.

Hooke, R. LeB., B. Hanson, N.R. Iverson, P. Jansson and U.H. Fischer 1997 Rheology of till beneath Storglaciären, Sweden. Journal of Glaciology 43, 172-179.

Hutter, K. and V. O. S. Olunloyo 1980 On the distribution of stress and velocity in an ice strip, which is partly sliding over and partly adhering to its bed, by using a Newtonian viscous approximation. Proceedings of the Royal Society of London, Series A, 373, 385-403.

Iverson, N. R., T. S. Hooyer and R. W. Baker 1998 Ring-shear studies of till deformation: Coulomb-plastic behaviour and distributed strain in glacier beds. Journal of Glaciology 44, 634-642.

Kamb, B. 1970 Sliding motion of glaciers: theory and observation. Reviews of Geophysics and Space Physics 8, 673-728.

Kamb, B. 1991 Rheological nonlinearity and flow instability in the deforming bed mechanism of ice stream motion. Journal of Geophysical Research 96, 16,58516,595 .

Kinahan, G. H. and M. H. Close 1872 The general glaciation of Iar-Connaught and its neighbourhood, in the counties of Galway and Mayo. Hodges, Foster and Co., Dublin, 20 pp.

Kleman, J. and C. Hattestrand 1999 Frozen-bed Fennoscandian and Laurentide ice sheets during the Last Glacial Maximum. it Nature 402, 63-66.

Lundqvist, J. 1989 Rogen (ribbed) moraine-identification and possible origin. Sedimentary Geology 62, 281-292.

Maslowe, S.A. 1985 Shear flow instabilities and transition. In: Hydrodynamic instabilities and the transition to turbulence, 2nd ed., eds. H.L. Swinney and J.P. Gollub, Topics in Applied Physics, Vol. 45, Springer-Verlag, Berlin, pp. $181-228$. 
Menzies, J.M. 1979 The mechanics of drumlin formation with particular reference to the change in pore-water content of the till. Journal of Glaciology 22, 373-384.

Menzies, J.M. and W.W. Shilts 1996 Subglacial environments. In: Past glacial environments: sediments, forms and techniques, ed. J. Menzies, pp. 15-136. Butterworth-Heinemann, Oxford.

Millis, J. 1911 What caused the drumlins? Science 34, 60-62.

Mitchell, J. K. 1993 Fundamentals of soil behaviour. 2nd ed., John Wiley, New York.

Nye, J. F. 1969 A calculation of the sliding of ice over a wavy surface using a Newtonian viscous approximation. Proceedings of the Royal Society of London, Series A, 311, 445-467.

Nye, J. F. 1970 Glacier sliding without cavitation in a linear viscous approximation. Proceedings of the Royal Society of London, Series A, 315, 381-403.

Richards, K. 1982 Rivers: form and process in alluvial channels. Methuen, London. Russell, I.C. 1895 The influence of debris on the flow of glaciers. Journal of Geology 3, 823-832.

Sharpe, D.R. 1987 The stratified nature of drumlins from Victoria Island and Southern Ontario, Canada. In Drumlin Symposium, eds. J. Menzies and J. Rose, Balkema, Rotterdam, pp. 185-214.

Shaw, J. 1983 Drumlin formation related to inverted meltwater erosional marks. Journal of Glaciology 29, 461-479.

Shaw, J. 1994 Hairpin erosional marks, horseshoe vortices and subglacial erosion. Sedimentary Geology 91, 269-283.

Shaw, J. and D. Kvill 1984 A glaciofluvial origin for drumlins of the Livingstone Lake area, Saskatchewan. Canadian Journal of Earth Sciences 21, 1442-1459. 
Shaw, J., D. Kvill and B. Rains 1989 Drumlins and catastrophic glacial floods. Sedimentary Geology 62, 177-202.

Smalley, I.J. and D.J. Unwin 1968 The formation and shape of drumlins and their distribution and orientation in drumlin fields. Journal of Glaciology 7, 377-390.

Sugden, D.A. and B.S. John 1976 Glaciers and landscape. Edward Arnold, London.

Tarr, R.S. 1894 The origin of drumlins. American Geologist 13, 393-407.

Upham, W. 1892 Conditions of accumulation of drumlins. American Geologist 10, $339-362$.

Walder, J.S. and A. Fowler 1994 Channelised subglacial drainage over a deformable bed. Journal of Glaciology 40, 3-15.

Weertman, J. R. 1957 On the sliding of glaciers. Journal of Glaciology 3, 33-38. 


\section{Figure captions}

Figure 1 Drumlins in the Ards Peninsula, County Down, Northern Ireland. Typical elevations are 30 metres and lengths several hundred metres. The photograph is taken from the top of one drumlin.

Figure 2 A field of drumlins in Saskatchewan. Ice flow was from the bottom left (Boulton 1987, page 66). This image is suggestive of a spatial instability, but one which is strongly influenced by inhomogeneity in the underlying substrate (whence the patchiness in the waveforms).

FIGURE 3 Subglacial till, from a coastally exposed drumlin at Killough, County Down, Northern Ireland. Irregular rock fragments are dispersed in a matrix of finer material.

FiguRE 4 Schematic geometry of the ice sheet and till flow.

Figure 5 Profiles of $q(s, \tau)$ calculated using (17); a value of $\alpha=10$ is used, and units are $\mathrm{m}^{2} \mathrm{y}^{-1}$ for till flux, while $s$ is given in metres. Graphs are shown for $\tau$ $=0.05,0.1,0.2$, and 0.3 bars. Other constants are taken as $\Delta \rho_{s w} g(1-n)=0.1$ bar $\mathrm{m}^{-1}, N=1$ bar, $A=10 \mathrm{y}^{-1}$.

FIGURE 6 Ice velocity as a function of till thickness, same parameters as in figure 5.

Figure 7 The instability functions $Q(X)$ and $J(X)$ in the definition of $\Delta_{2}$.

Figure 8 The function $F(X)$ as used in (42). $F \rightarrow 1$ as $X \rightarrow \infty$.

FiguRE 9 The curves $\Delta_{1}=0$ and $\Delta_{2}=0$ given by (49) in terms of the parameters $X=\alpha r \tau s / N^{2}$ and $Y=\alpha \tau / N$, when $K=120$. Instability occurs between the two curves.

Figure 10 The functions $D(X, Y), B(X, Y)$ and $C(X)$ defined in (54).

Figure 11 The maximum growth rate as a function of $X$ and $Y$, given by the large $K$ approximation (56). $\rho_{\max }$ is put to zero where the system is stable, i.e. for $Y<F(X)$, and this curve is delineated on the $(X, Y)$ plane. The units of 
growth rate are $(A N / 2 \mu)^{1 / 2}$, and for representative values may be taken as $\mathrm{y}^{-1}$. Note that $X$ lies in the range $0.5<X<5$.

FiguRE 12 The wavelength of the most rapidly growing mode. The units are $k^{*-1} / 100=$ $(2 \mu A N)^{1 / 2} / 100 r$, and for $k^{*-1}=100 \mathrm{~m}$, this means the units are $\mathrm{m}$.

FiguRE 13 The wave speed of the most rapidly growing mode. The units are $u^{*} / 100$, i.e. $(A N / r) / 100$, and for $(A N / r)=100 \mathrm{~m} \mathrm{y}^{-1}$, the units are $\mathrm{m} \mathrm{y}^{-1}$. The wave speed is less than the basal ice velocity, but the two are roughly comparable. The relatively high values are purely due to our choice of the rheological constant $A$. It should be noted that the $Y$ range in this figure and in figure 13 is $F(X)<Y<F(X)+4$, and the surface extends beyond the line $Y=4$.

Figure 14 The same instability region as shown in figure 9 , but in terms of the primary instability parameters $\xi=r s / N$ and $Y=\alpha \tau / N$. See the comment on surface plotting in figure 12 . 


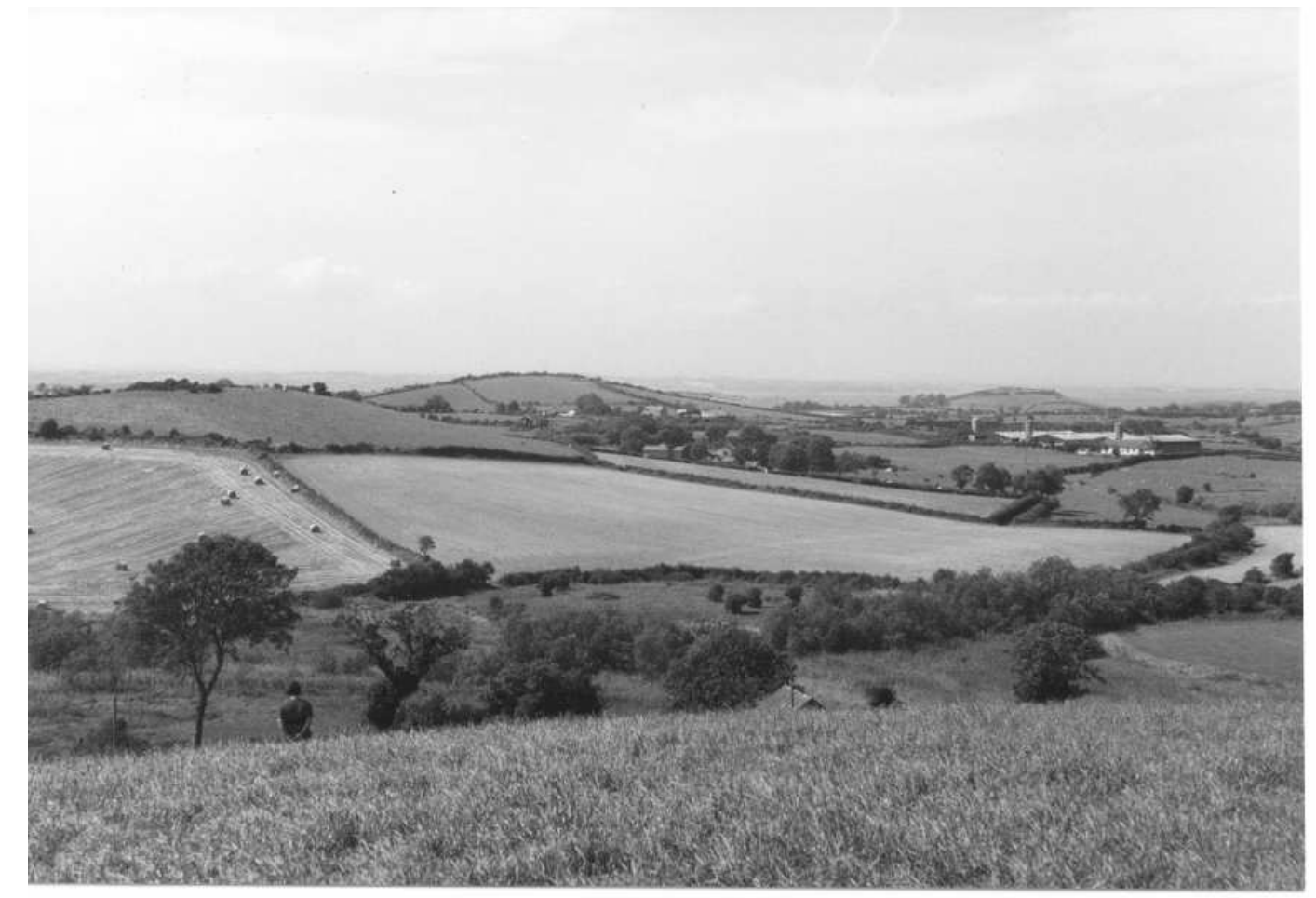

Figure 1: Drumlins in the Ards Peninsula, County Down, Northern Ireland. Typical elevations are 30 metres and lengths several hundred metres. The photograph is taken from the top of one drumlin. 


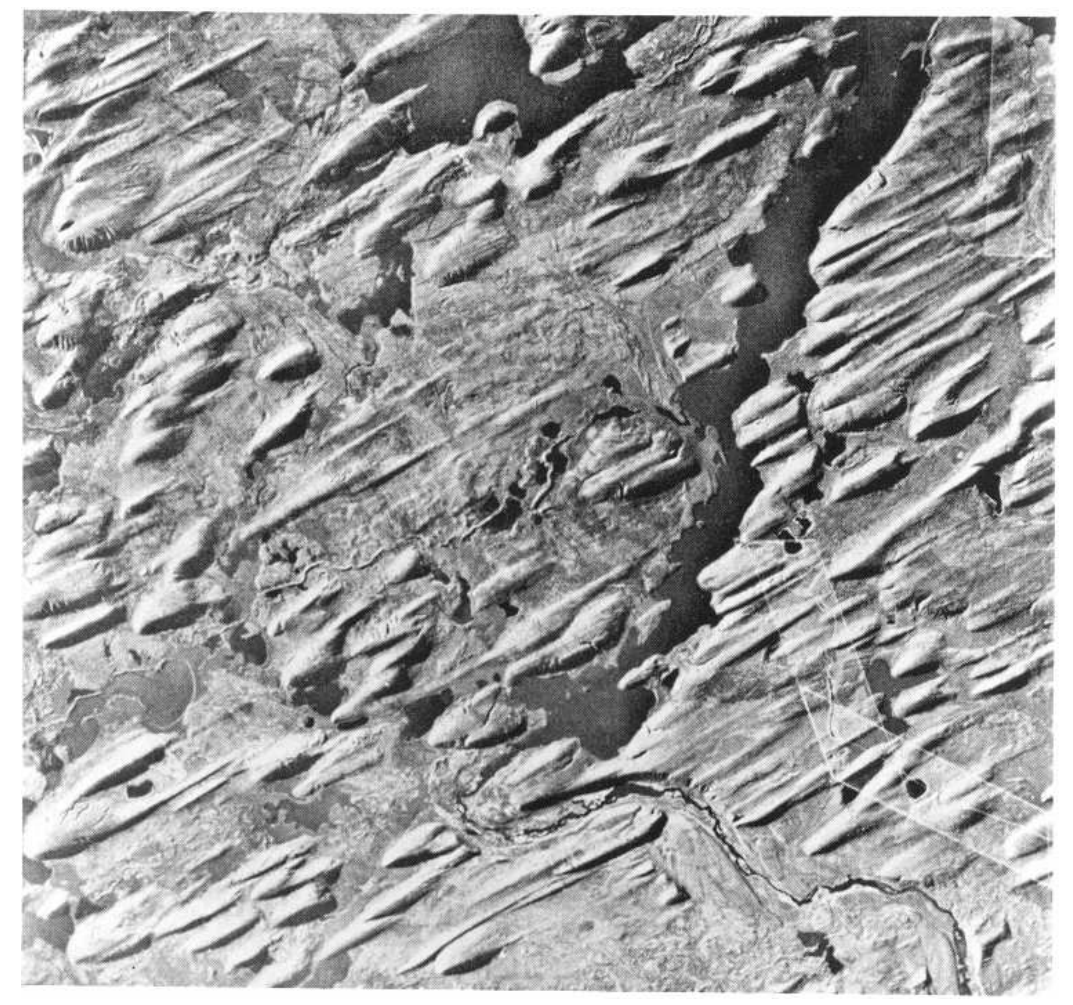

Figure 2: A field of drumlins in Saskatchewan. Ice flow was from the bottom left (Boulton 1987, page 66). This image is suggestive of a spatial instability, but one which is strongly influenced by inhomogeneity in the underlying substrate (whence the patchiness in the waveforms). 


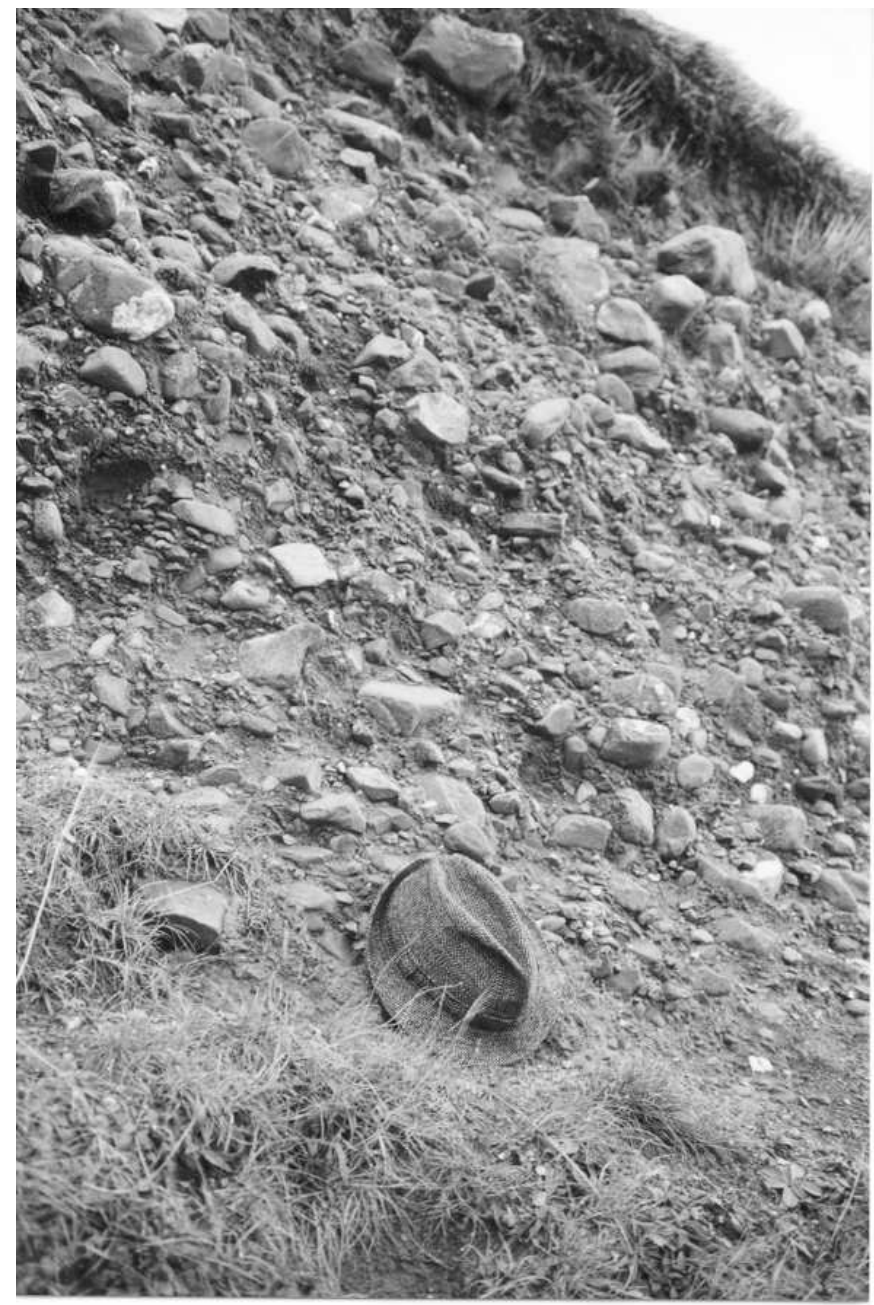

Figure 3: Subglacial till, from a coastally exposed drumlin at Killough, County Down, Northern Ireland. Irregular rock fragments are dispersed in a matrix of finer material. 


$$
\mathrm{z}=\mathrm{z}_{\mathrm{i}}
$$

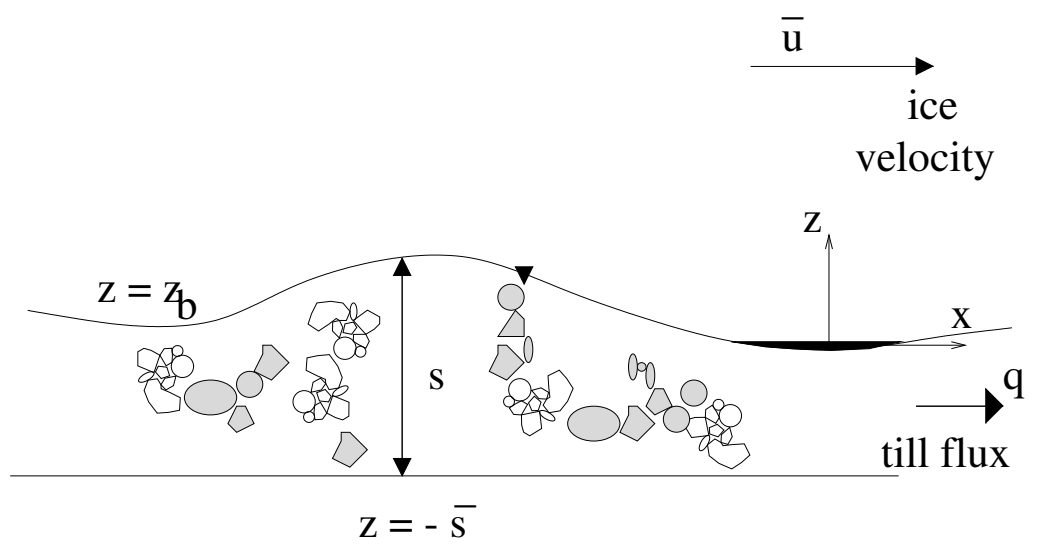

Figure 4: Schematic geometry of the ice sheet and till flow. 


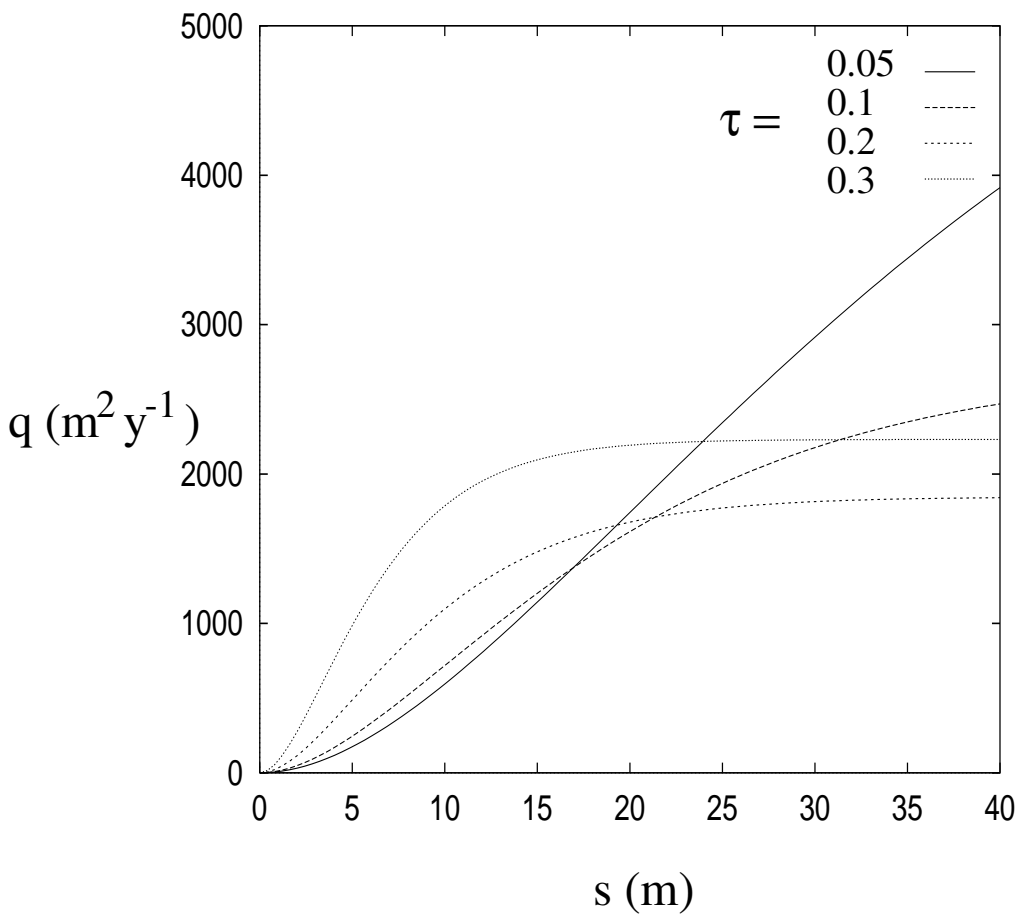

Figure 5: Profiles of $q(s, \tau)$ calculated using (17); a value of $\alpha=10$ is used, and units are $\mathrm{m}^{2} \mathrm{y}^{-1}$ for till flux, while $s$ is given in metres. Graphs are shown for $\tau=0.05$, $0.1,0.2$, and 0.3 bars. Other constants are taken as $\Delta \rho_{s w} g(1-n)=0.1 \mathrm{bar} \mathrm{m}^{-1}$, $N=1$ bar, $A=10 \mathrm{y}^{-1}$. 


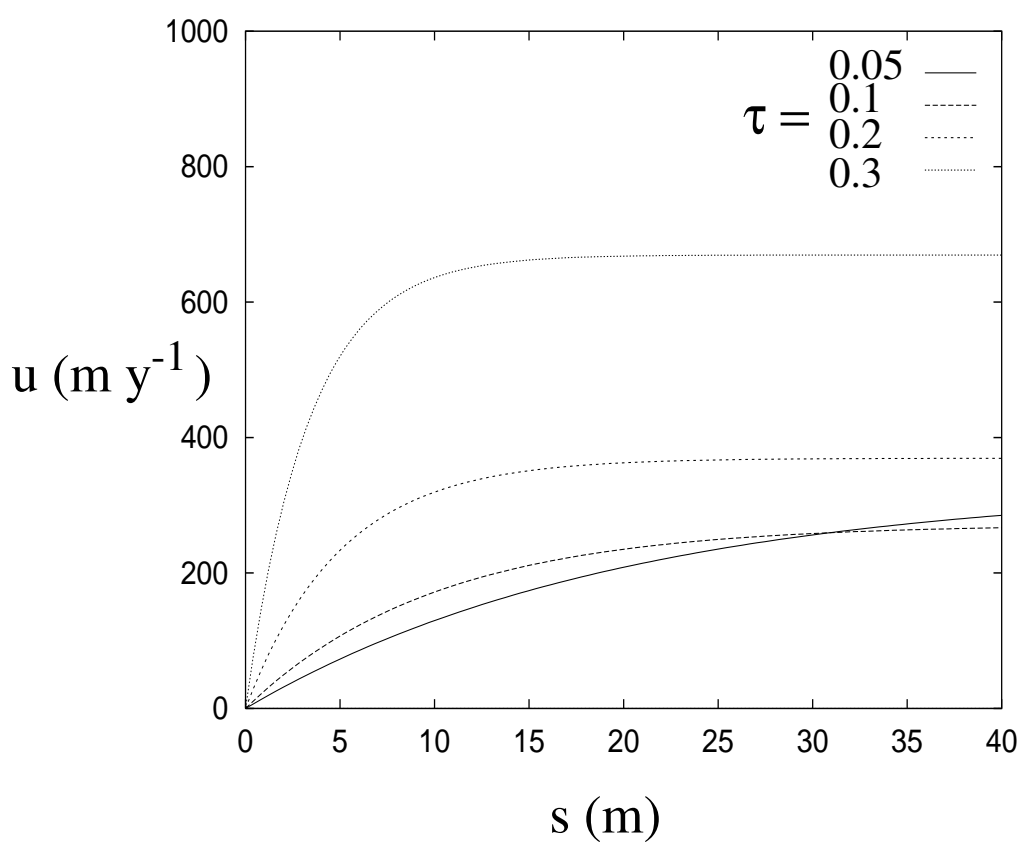

Figure 6: Ice velocity as a function of till thickness, same parameters as in figure 5 . 


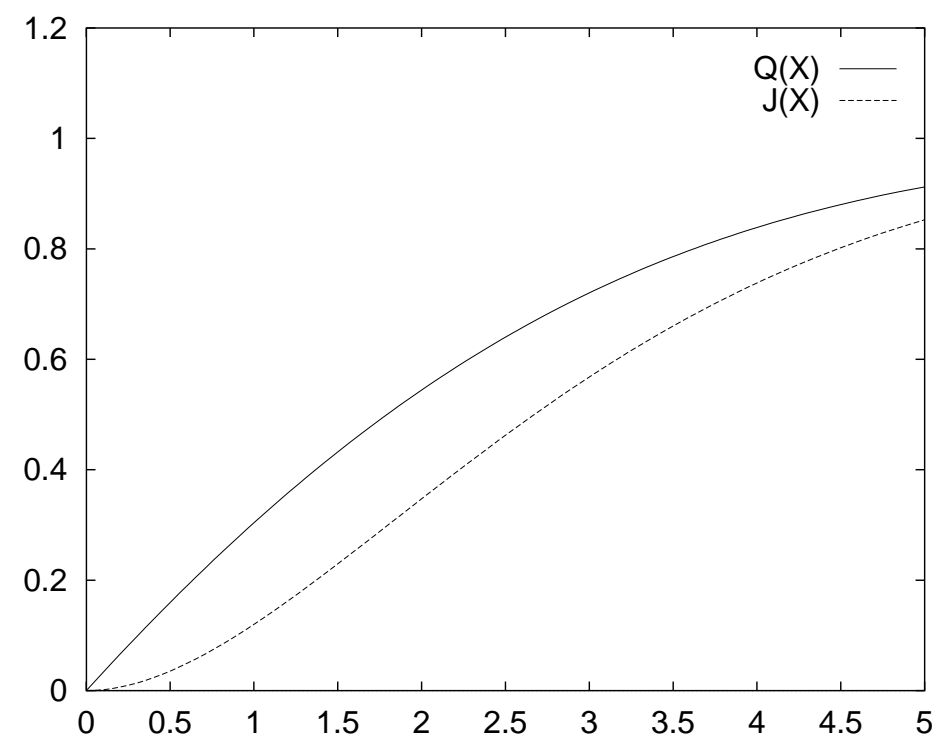

Figure 7: The instability functions $Q(X)$ and $J(X)$ in the definition of $\Delta_{2}$. 


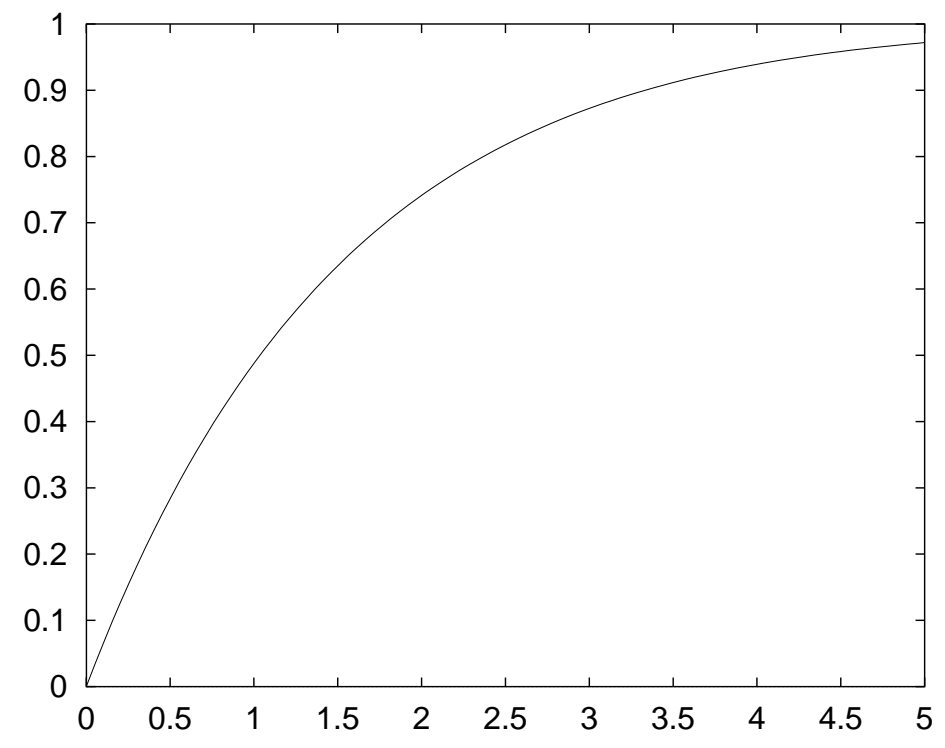

Figure 8: The function $F(X)$ as used in (42). $F \rightarrow 1$ as $X \rightarrow \infty$. 


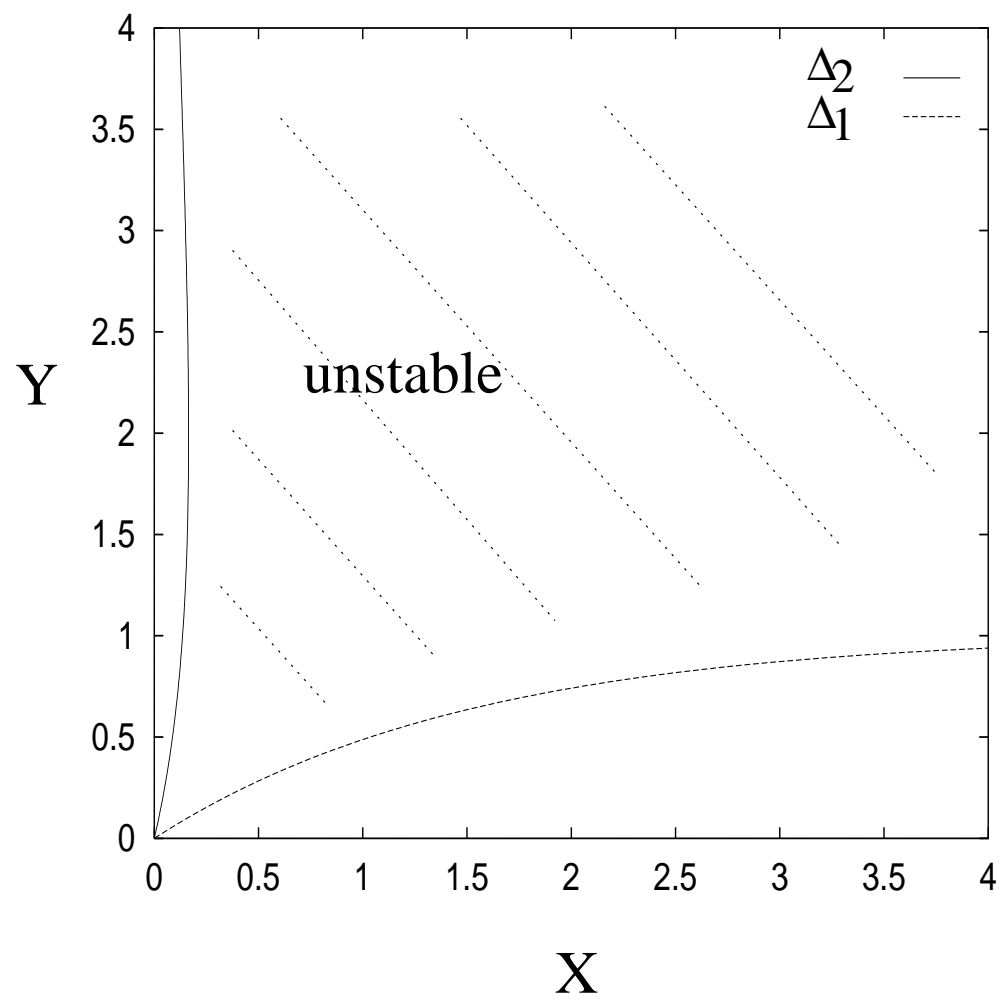

Figure 9: The curves $\Delta_{1}=0$ and $\Delta_{2}=0$ given by (49) in terms of the parameters $X=\alpha r \tau s / N^{2}$ and $Y=\alpha \tau / N$, when $K=120$. Instability occurs between the two curves. 

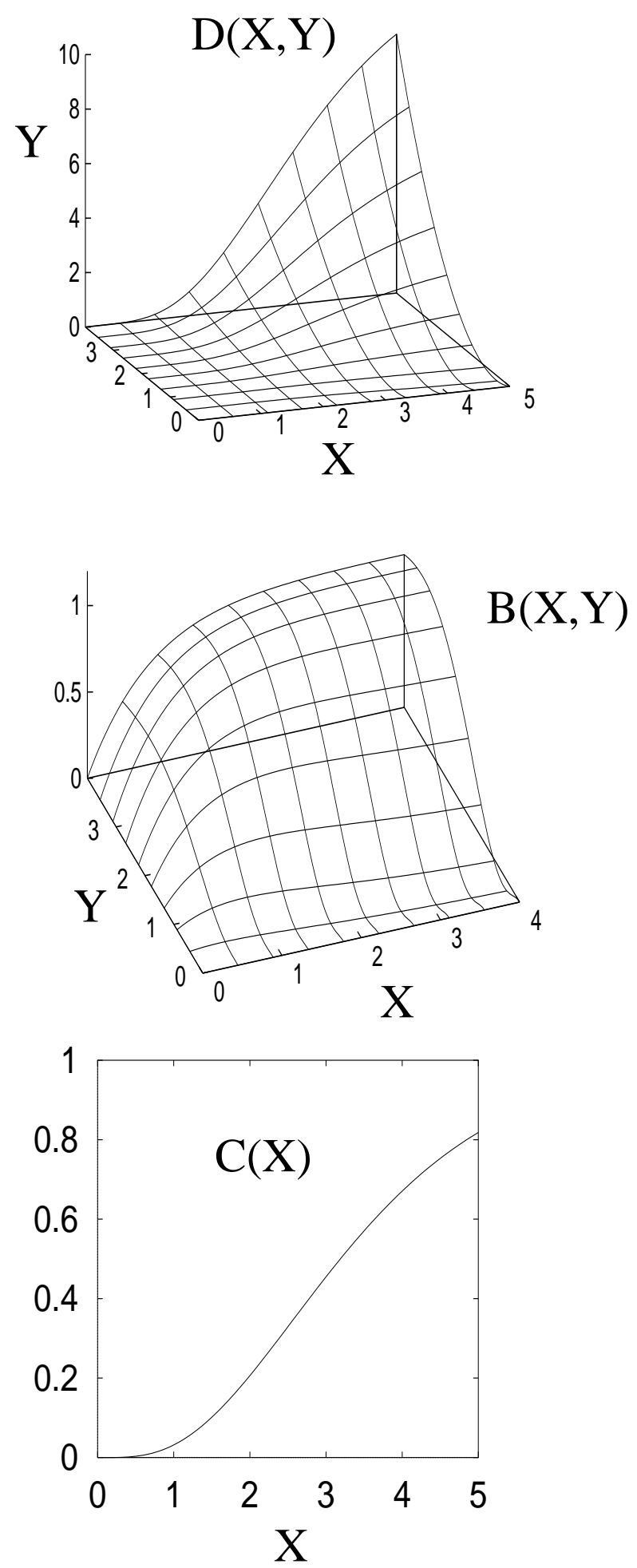

Figure 10: The functions $D(X, Y), B(X, Y)$ and $C(X)$ defined in (54). 


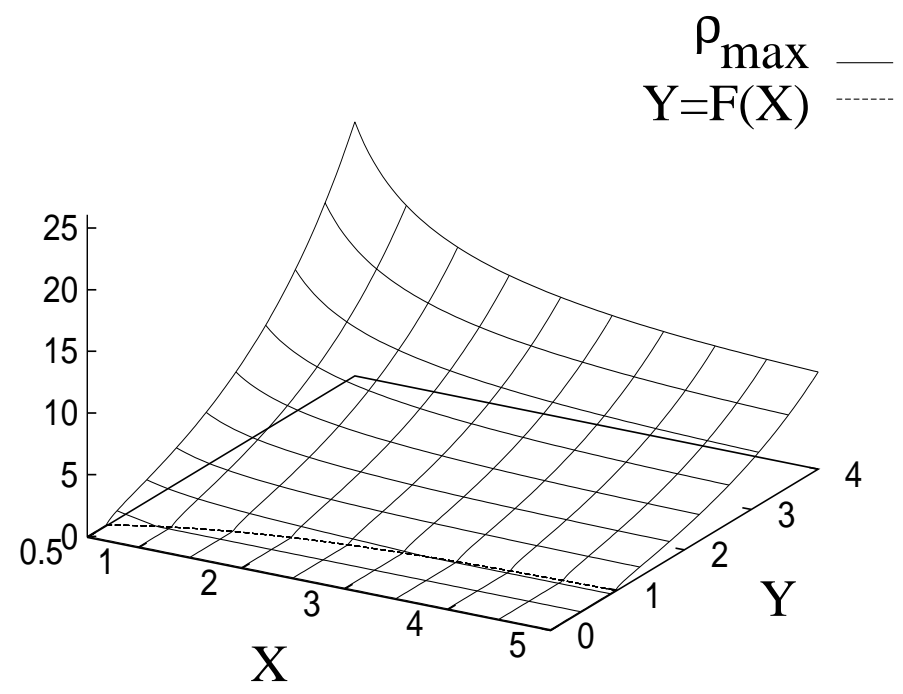

Figure 11: The maximum growth rate as a function of $X$ and $Y$, given by the large $K$ approximation (56). $\rho_{\max }$ is put to zero where the system is stable, i.e. for $Y<F(X)$, and this curve is delineated on the $(X, Y)$ plane. The units of growth rate are $(A N / 2 \mu)^{1 / 2}$, and for representative values may be taken as $\mathrm{y}^{-1}$. Note that $X$ lies in the range $0.5<X<5$. 


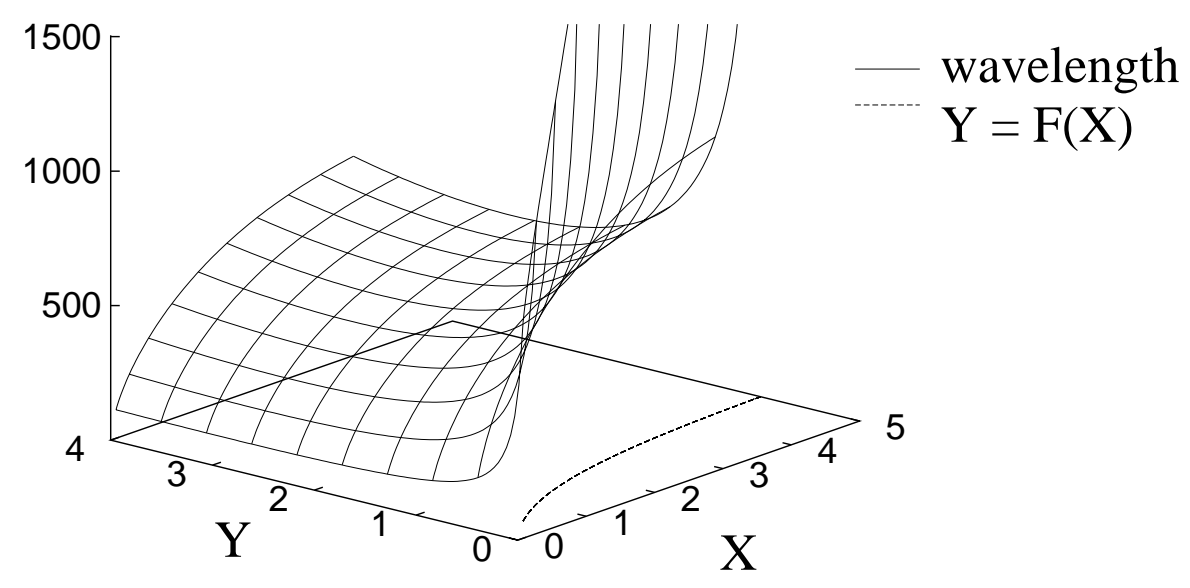

Figure 12: The wavelength of the most rapidly growing mode. The units are $k^{*-1} / 100=(2 \mu A N)^{1 / 2} / 100 r$, and for $k^{*-1}=100 \mathrm{~m}$, this means the units are $\mathrm{m}$. It should be noted that the $Y$ range in this figure and in figure 13 is $F(X)<Y<$ $F(X)+4$, and the surface extends beyond the line $Y=4$. 


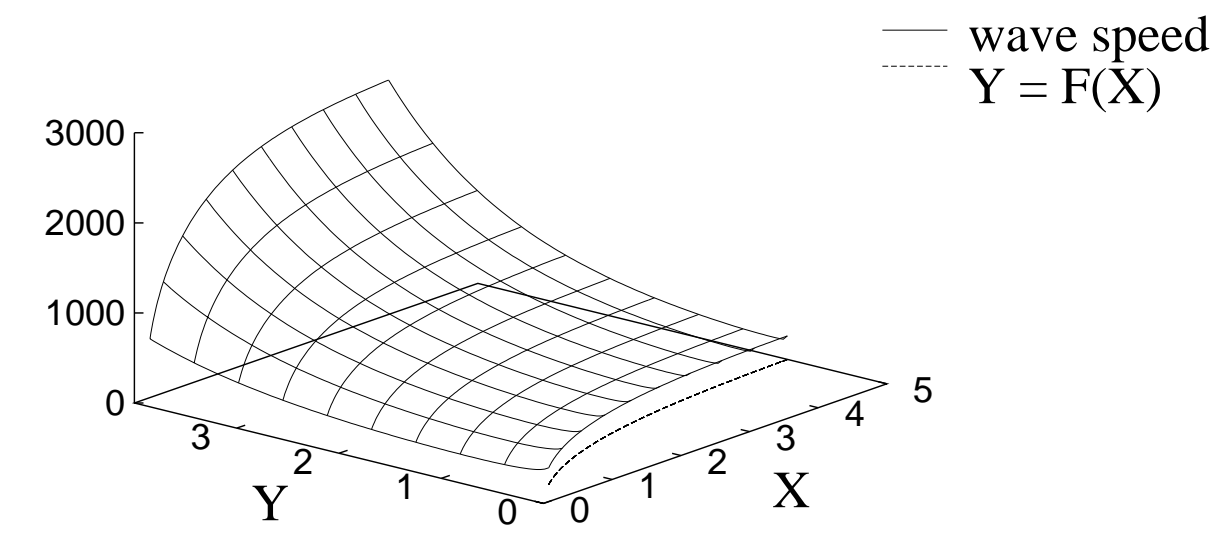

Figure 13: The wave speed of the most rapidly growing mode. The units are $u^{*} / 100$, i.e. $(A N / r) / 100$, and for $(A N / r)=100 \mathrm{~m} \mathrm{y}^{-1}$, the units are $\mathrm{m} \mathrm{y}^{-1}$. The wave speed is less than the basal ice velocity, but the two are roughly comparable. The relatively high values are purely due to our choice of the rheological constant $A$. See the comment on surface plotting in figure 12 . 


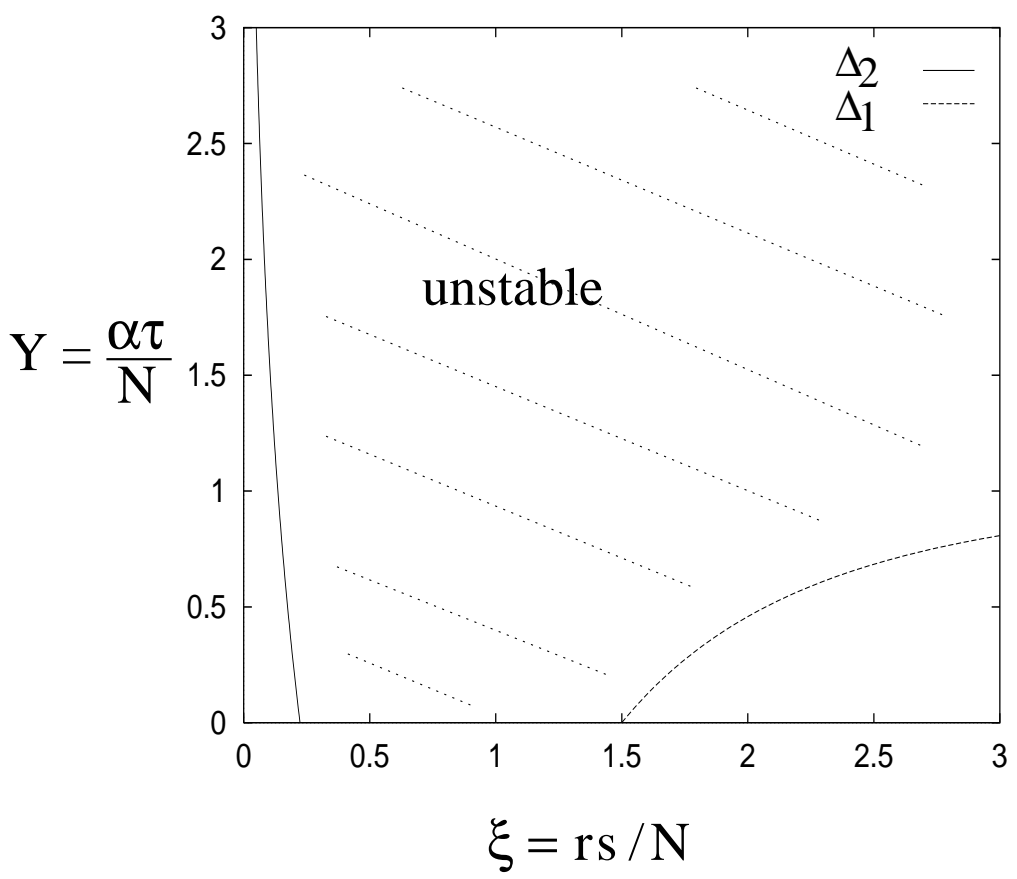

Figure 14: The same instability region as shown in figure 9 , but in terms of the primary instability parameters $\xi=r s / N$ and $Y=\alpha \tau / N$. 